\title{
Propagation of the 2001-2002 silent earthquake and interplate coupling in the Oaxaca subduction zone, Mexico
}

\author{
S. I. Franco ${ }^{1}$, V. Kostoglodov ${ }^{1}$, K. M. Larson ${ }^{2}$, V. C. Manea ${ }^{3}$, M. Manea ${ }^{3}$, and J. A. Santiago ${ }^{1}$ \\ ${ }^{1}$ Institudo de Geofísica, Universidad Nacional Autónoma de México, Ciudad Universitaria, Del. Coyoacan, 04510 Mexico D.F., Mexico \\ ${ }^{2}$ Department of Aerospace Engineering Sciences, University of Colorado, Boulder, CO 80309-0429, USA \\ ${ }^{3}$ California Institute of Technology, Seismological Laboratory, Pasadena, CA, MS 252-21, USA
}

(Received November 18, 2004; Revised September 30, 2005; Accepted September 30, 2005)

\begin{abstract}
The aseismic slow slip event of 2001-2002 in Guerrero, Mexico, with an equivalent magnitude $M_{W} \sim 7.5$, is the largest silent earthquake (SQ) among many recently recorded by GPS in different subduction zones (i.e. Japan, Alaska, Cascadia, New Zealand). The sub-horizontal and shallow plate interface in Central Mexico is responsible for specific conditions for the $\sim 100 \mathrm{~km}$ long extended transient zone where the SQs develop from $\sim 80$ to $\sim 190 \mathrm{~km}$ inland from the trench. This wide transient zone and relatively large slow slips of 10 to 20 $\mathrm{cm}$ displacements on the subduction fault result in noticeable surface displacements of 5-6 cm during the SQs. Continuous GPS stations allow one to trace the propagation of SQs, and to estimate their arrival time, duration and geometric attenuation. These propagation parameters must be accounted in order to locate source of slow slips events and to understand the triggering effect that they have on large subduction earthquakes. We use longbaseline tiltmeter data to define new time limits (onset and duration) for the SQs and continuous records from 8 GPS stations to determine the propagation of the 2001-2002 SQ in Central Mexico. Data from the CAYA and IGUA GPS stations, separated by $\sim 170 \mathrm{~km}$ and located along the profile perpendicular to the trench, are used to determine that the surface deformation from the 2001-2002 SQ started almost instantaneously. It propagated parallel to the coast at $\sim 2 \mathrm{~km}$ /day with an exponential attenuation of the horizontal surface displacement and a linear decrease of its duration with distance. Campaign data obtained yearly from 2001 to 2005 at the Oaxaca GPS network have been modeled according to a propagation of the 2001-2002 SQ step-like displacement anomaly. This modeling shows that the SQ ceased gradually in the central part of the Oaxaca segment of the subduction zone (west of Puerto Angel, PUAN) and then it apparently triggered another SQ in SE Oaxaca (between PUAN and Salina Cruz, SACR). The estimated horizontal velocities for inter-event epochs at each GPS site are used to assess an average interplate coupling in the Central Oaxaca subduction zone.
\end{abstract}

Key words: Subduction, silent earthquakes, propagation, coupling ratio, GPS, Mexico.

\section{Introduction}

Recent discoveries of aseismic slow slip events (SSE) or silent earthquakes (SQ) (see a classification of slow slip events by Kawasaki, 2004) in the subduction zones of Japan (i.e; Hirose et al., 1999; Ozawa et al., 2002; Sagiya and Ozawa, 2002; Sagiya, 2004), Cascadia (Dragert et al., 2001), Alaska (Freymueller et al., 2002), New Zealand (Beavan et al., 2003; Douglas et al., 2005), and Mexico (Lowry et al., 2001; Kostoglodov et al., 2003; Larson et al., 2004) are one of the most interesting observations in studies in the seismotectonics of subduction zones. Modern GPS techniques can resolve less-than-cm surface displacements caused by SQs, as observed in the Cascadia subduction zone (Dragert et al., 2001; Miller et al., 2002). Detailed estimates of propagation characteristics of small amplitude SQs (i.e. Melbourne et al., 2005), however, are still problematic due to the low signal to noise ratio of the measurements. In constrast, relatively large (up to 5-6 cm) horizontal displacements produced by SQs in the Central Mex-

Copyright (c) The Society of Geomagnetism and Earth, Planetary and Space Sciences (SGEPSS); The Seismological Society of Japan; The Volcanological Society of Japan; The Geodetic Society of Japan; The Japanese Society for Planetary Sciences; TERRAPUB ican subduction zone over distances of 200-500 km (Kostoglodov et al., 2003), allows one to trace the arrival time and to determine the duration and attenuation of the deformation signal of SQ propagation.

The "Sismologia-UNAM" GPS network (http://tlacaelel. igeofcu.unam.mx/ vladimir/gpsred/gpsred.html) has been established with the aim to understand the subductionrelated seismotectonic regime in Central Mexico. This network .has recorded to date three well-defined SQs in the state of Guerrero (Fig. 1). The first slow slip event recorded, which occurred during 1995-1996, was preceded by the $1995 M_{W}=7.4$ Copala earthquake (Anderson et al., 1995). The maximum surface displacement due to this $S Q$, recorded on the campaign sites, was almost $4 \mathrm{~cm}$ (Larson et al., 2004). The second SQ recorded occurred during 1998 in the Guerrero seismic gap (Lowry et al., 2001). This event was recorded by the CAYA and POSW permanent stations (Fig. 1), and the obtained horizontal displacements were 2.6 and $1 \mathrm{~cm}$, respectively (Larson et al., 2004). The largest aseismic slow slip event recorded in the area (with a surface displacement range of about $2.4-6 \mathrm{~cm}$ ) started in October 2001 in the same area as the 1998 SQ; it lasted for $6-7$ months and extended over an area of $\sim 550 \times 250$ 


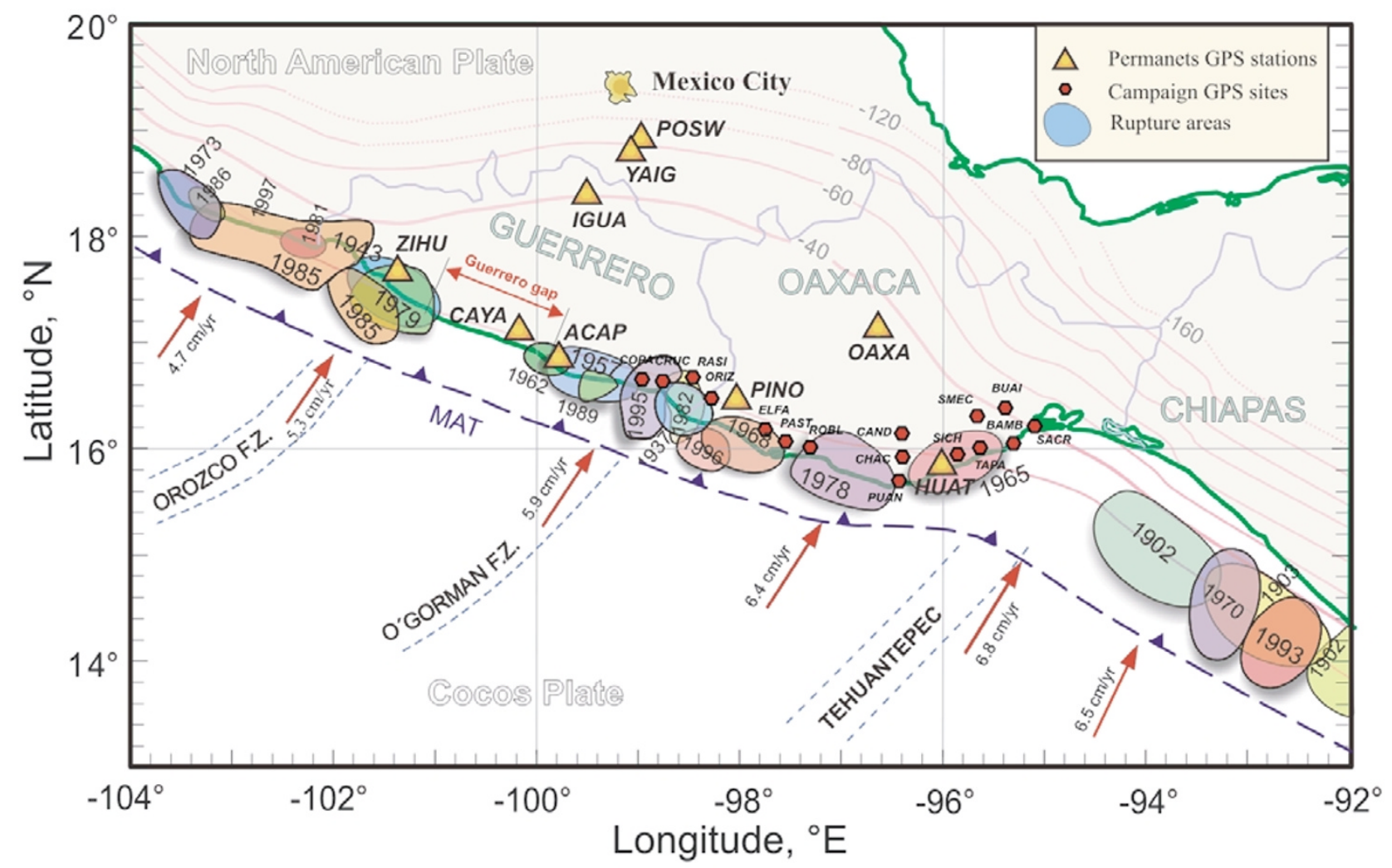

Fig. 1. The study area encompasses Guerrero and Oaxaca states of Mexico. Shaded ellipse-like areas annotated with the years are rupture areas of the most recent major thrust earthquakes $(M \geq 6.5)$ in the Mexican subduction zone. Triangles show locations of permanent GPS stations. Small hexagons indicate campaign GPS sites. Arrows are the Cocos-North America convergence vectors from NUVEL-1A model (DeMets et al., 1994). Double head arrow shows the extent of the Guerrero seismic gap. Solid and dashed curves annotated with negative numbers show the depth in km down to the surface of subducting Cocos plate (modified from Pardo and Suárez, 1995, using the plate interface configuration model for the Central Oaxaca from this study, the model for Guerrero from Kostoglodov et al. (1996), and the last seismological estimates in Chiapas by Bravo et al. (2004). MAT, Middle America trench.

$\mathrm{km}^{2}$. (Kostoglodov et al., 2003) The equivalent magnitude of this slow slip event was estimated as $M_{W}=7.5$ with a maximum modeled displacement on the plate interface of $\sim 22.5 \mathrm{~cm}$ (Iglesias et al., 2004). Position records from 8 continuous GPS stations (Fig. 2) clearly show a slow propagation of the 2001-2002 SQ with a rate of several km/day (Kostoglodov et al., 2003).

In this paper we compare the data acquired during the 2001-2002 SQ by a long-baseline tiltmeter (Kostoglodov et al., 2002), with data obtained from the nearby permanent GPS station ACAP, to ascertain that the duration of the SQ is twice as long as the apparent active phase of the event. We then obtain new onset times, duration and attenuation of the 2001-2002 SQ.

The sparse coverage of permanent GPS restricts detailed tracking of SQs through the state of Oaxaca. Occupation measurements carried out yearly since 2001 at the Oaxaca GPS sites (Fig. 1) combine the effect of the interevent steady-state motion and the aseismic slow slip displacements, and do not show significant changes in GPS positions due to the SQ. Assuming that the 2001-2002 slow slip crustal deformation propagated into Oaxaca with a velocity and a duration-distance relation (both estimated through continuous GPS records), all five sets of campaign data (2001-2005) can be fit with a modeled step-like displacement signal at each GPS site. This procedure would provide some constrained (by onsets and durations) estimates of the amplitudes (U) of anomalous displacement during the SQ. The GPS sites, where U values match the attenuation-distance relation determined from the continuous GPS records, most likely "felt" the SQ event. In this work we applied this SQ tracking method to all campaign GPS sites in Oaxaca. The results support the hypothesis that the 2001-2002 SQ propagated only in the western part of Oaxaca, it ran out in the central part and, probably triggered a smaller SQ in the southeastern part of the Oaxaca subduction zone.

The fitting of campaign GPS data with the sigmoid-shape displacement signal (Larson et al., 2004) yields estimates of anomalous U and some independent "inter-event" steadystate velocities (velocities from GPS sites between SQs). These velocities may be used to model average interplate coupling for the inter-event stage of the seismic cycle.

\section{Seismotectonic Setting}

The convergence of the Cocos and North American plates along the Middle America Trench (MAT) is responsible for the crustal deformation and large subduction thrust earthquakes in Mexico (Fig. 1). The relative convergence rate in the MAT varies in Mexico from $5.3 \mathrm{~cm} / \mathrm{yr}$ in eastern Guerrero up to $6.5 \mathrm{~cm} / \mathrm{yr}$ in southeastern Oaxaca (DeMets et al., 1994). The age of the Cocos plate in the Guerrero-Oaxaca 


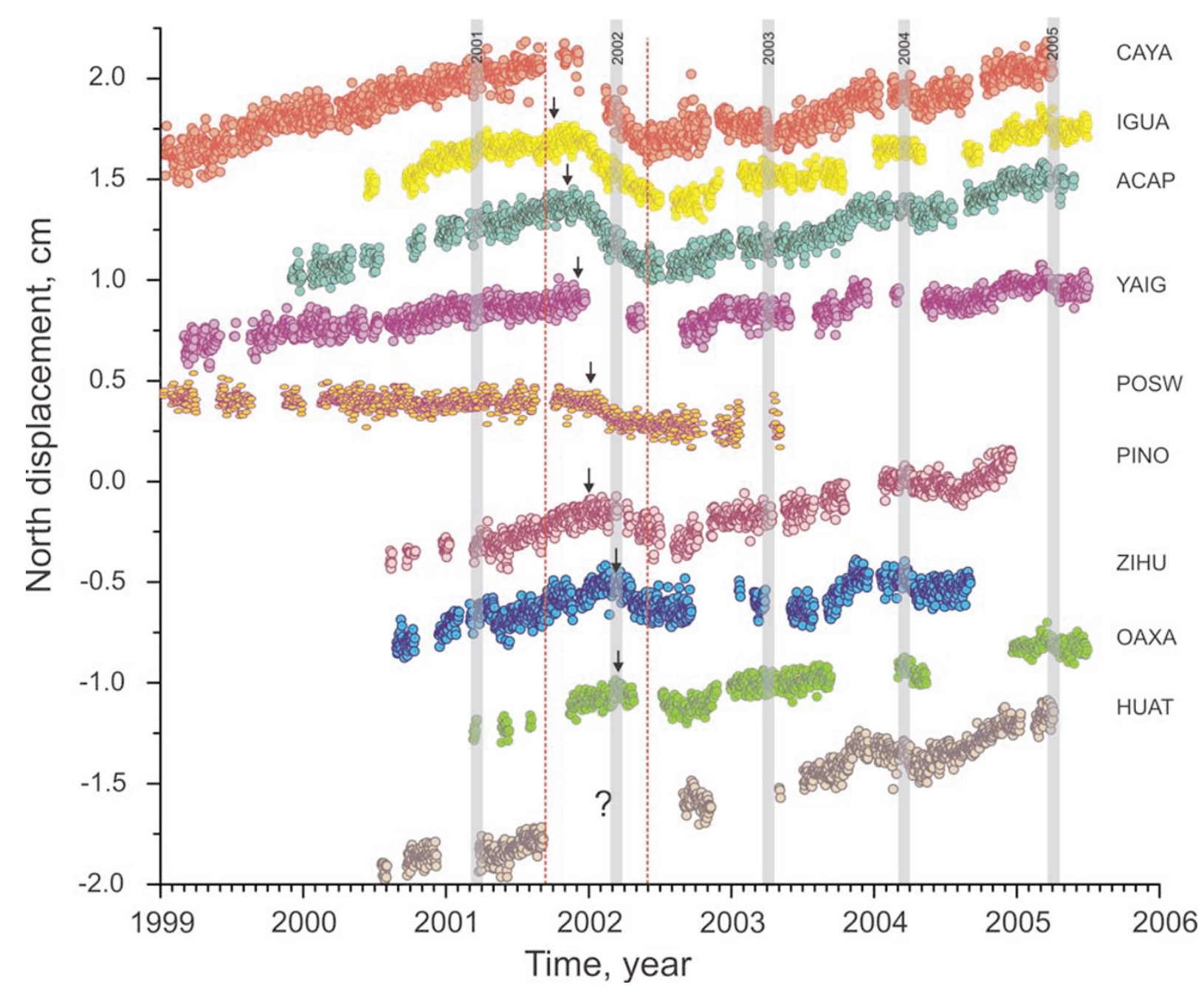

Fig. 2. Daily time series of north position component (relative to the NOAM plate) of the permanent GPS stations. Dashed vertical lines mark apparent initial and ending dates of the silent earthquake at CAYA station. Arrows indicate the onsets of the 2001-2002 slow slip at different stations. Some GPS records are not complete because of equipment failures. Shaded vertical bands show the survey periods at the campaign GPS sites. The time series are ordered with respect to its distance from CAYA.

segment of the MAT is less than $16 \mathrm{Ma}$ (Kostoglodov and Bandy, 1995). The plate interface is sub-horizontal in Guerrero (Kostoglodov et al., 1996) and Central Oaxaca (TorresZamudio, 2002), and gradually steepens toward southeastern Oaxaca (Pardo and Suarez, 1995; Bravo et al., 2004).

An important factor which may influence seismic activity, crustal deformation and interplate coupling is the subduction of ocean floor bathymetric irregularities like subduction of the Tehuantepec ridge below the North American plate in the southeastern Oaxaca area, where a low degree of plate coupling would explain the relative deficiency of large earthquakes in the area (Fig. 1). In Guerrero, subduction of the O'Gorman and Orozco fracture zones correlates with a relatively frequent occurrence of $M_{W}=7.5-7.8$ thrust earthquakes (i.e., Kostoglodov and Ponce, 1994). A mature seismic gap in Central Guerrero has developed; since the last major subduction event in 1911 (Fig. 1) it has accumulated enough elastic energy for the next $M_{W} \sim 8.0$ thrust earthquake. It is noteworthy that the 1998 and 2001-2002 silent earthquakes initiated somewhere close to the center of this gap, downdip of the locked seismogenic zone (Lowry et al., 2001; Kostoglodov et al., 2003).
In the central part of Oaxaca, characteristic thrust earthquakes with an average magnitude of $M_{W} \sim 7.5$ are frequent (Singh et al., 1981, 1983). Figure 1 shows the estimated rupture areas of recent major thrust earthquakes that occurred in this zone since 1960. Singh et al. (2000) argued that the plate interface in Oaxaca is strongly coupled to a depth of approximately $80 \mathrm{~km}$, which is probably a too high value compared to the Guerrero seismogenic width (Suarez et al., 1990). It is also possible that the coupling at a subduction zone may vary with time since the last large subduction earthquake.

\section{Data Acquisition and Analysis}

The GPS network in Oaxaca includes 3 permanent stations (OAXA, HUAT and PINO) and 16 campaign sites, mainly located along the coast (Fig. 1). The GPS network in Guerrero, at the time of this study, consisted of 4 permanent stations (CAYA, ZIHU, ACAP and IGUA). In this work we use continuous records from the YAIG and POSW continuous GPS stations, to the north of Guerrero state (Fig. 1).

All campaign surveys in Oaxaca were carried out yearly from 2001-2005 during the same dry seasons in order to 


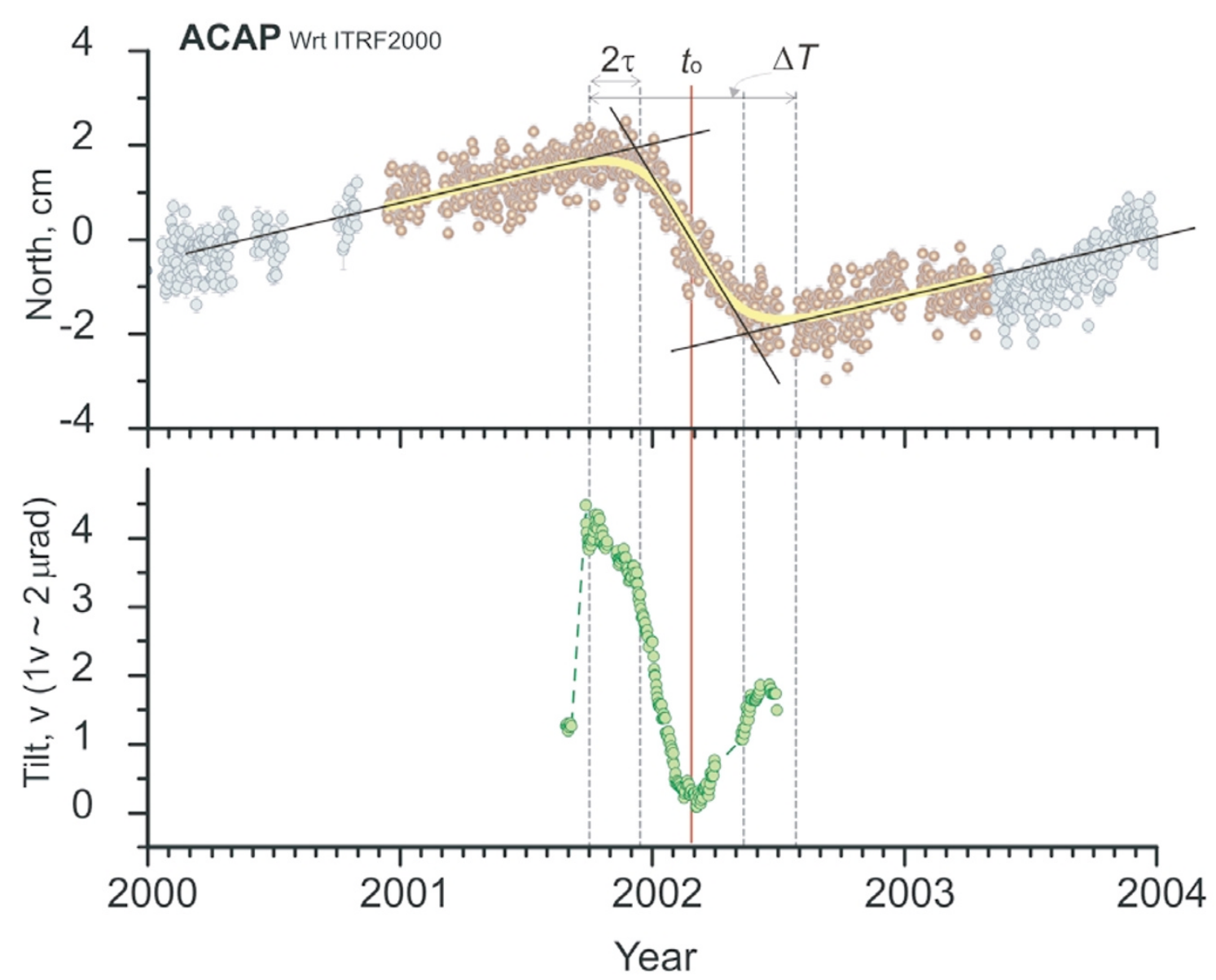

Fig. 3. Comparison between the daily averaged time series of the ACAP permanent GPS station (north GPS component shown at the top chart) and the Long Base Tiltmeter (LBT). As the ACAP GPS is located very close to the LBT, both stations recorded an anomalous deformation produced by 2001-2002 silent earthquake almost simultaneously. The onset and duration time of the SQ is clearly seen on the LBT record. $t_{0}$ is the median time of the SQ anomalous displacement, and $\tau$ is characteristic time. The duration of the SQ is $\Delta T=8 \tau$. The linear fit can also give a good estimation of the propagation parameters when corrected for $2 \tau$ early onset of the SQ and $4 \tau$ longer duration.

minimize the effect of variable weather conditions. The measurements at most of the sites were continuous for 72 hours. The sampling rate is 30 seconds.

The GPS data used in this study were analyzed with the GIPSY software (Lichten and Border, 1987) which uses both carrier phase and pseudorange observables. Data processing was performed using a Precise Point Positioning (PPP) strategy, which analyzes one station at a time (Zumberge et al., 1997). Precise clocks and orbits are provided by JPL. The GPS station coordinates are first estimated in a non-fiducial reference frame (Heflin et al., 1992) and then are transformed into ITRF2000 (International Reference Frame 2000; Boucher et al., 2003) using Helmert transformation parameters supplied by JPL.

Inter-event velocities $(V)$ (Fig. 8) and anomalous displacements $(U)$ during the 2001-2002 SQ at every GPS station and campaign sites were estimated by weighted fit of the sigmoid function to the daily positions. These velocities were then converted from ITRF2000 into a North America reference frame using the net NOAM velocity (Altamimi et al., 2002). Campaign data are not sufficient to determine seasonal effects and antenna blunders. These effects should be considered as a part of our uncertainty estimates. Mao et al. (1999) showed that the contribution of white, flicker, and random walk noise components into the uncertainties of the permanent GPS records is significant. To scale the formal standard errors of GPS data we used a scaling factor of 2 for both longitude and latitude position components following Marquez-Azua and DeMets (2003).

A function used to fit the GPS coordinate time series and estimate the SQ displacements is of the form analogous to that in Larson et al. (2004):

$$
y(t)=y_{0}+V t+U\left[1+\exp \left(\frac{t-t_{0}}{\tau}\right)\right]^{-1},
$$

where $y(t)$ is GPS site coordinate at time $t, y_{0}$ is coordinate at a reference time, $V$ is steady-state velocity, $U$ is anomalous displacement during the transient events, $t_{0}$ is the median time of the SQ event, and $\tau$ scales the period over which the event occurred. If $t_{0}$ and $\tau$ are specified, the other parameter $U$ can be estimated from least squares inversion.

In previous studies (i.e. Kostoglodov et al., 2003; Iglesias et al., 2004) the onset time and duration of the SQ were estimated approximately as $T_{1}=t_{0}-2 \tau$ and $\Delta T=4 \tau$, respectively. Here we compare the data from a long baseline tiltmeter (LBT) (Kostoglodov et al., 2002) and the nearest permanent GPS station (ACAP), which simultaneously 


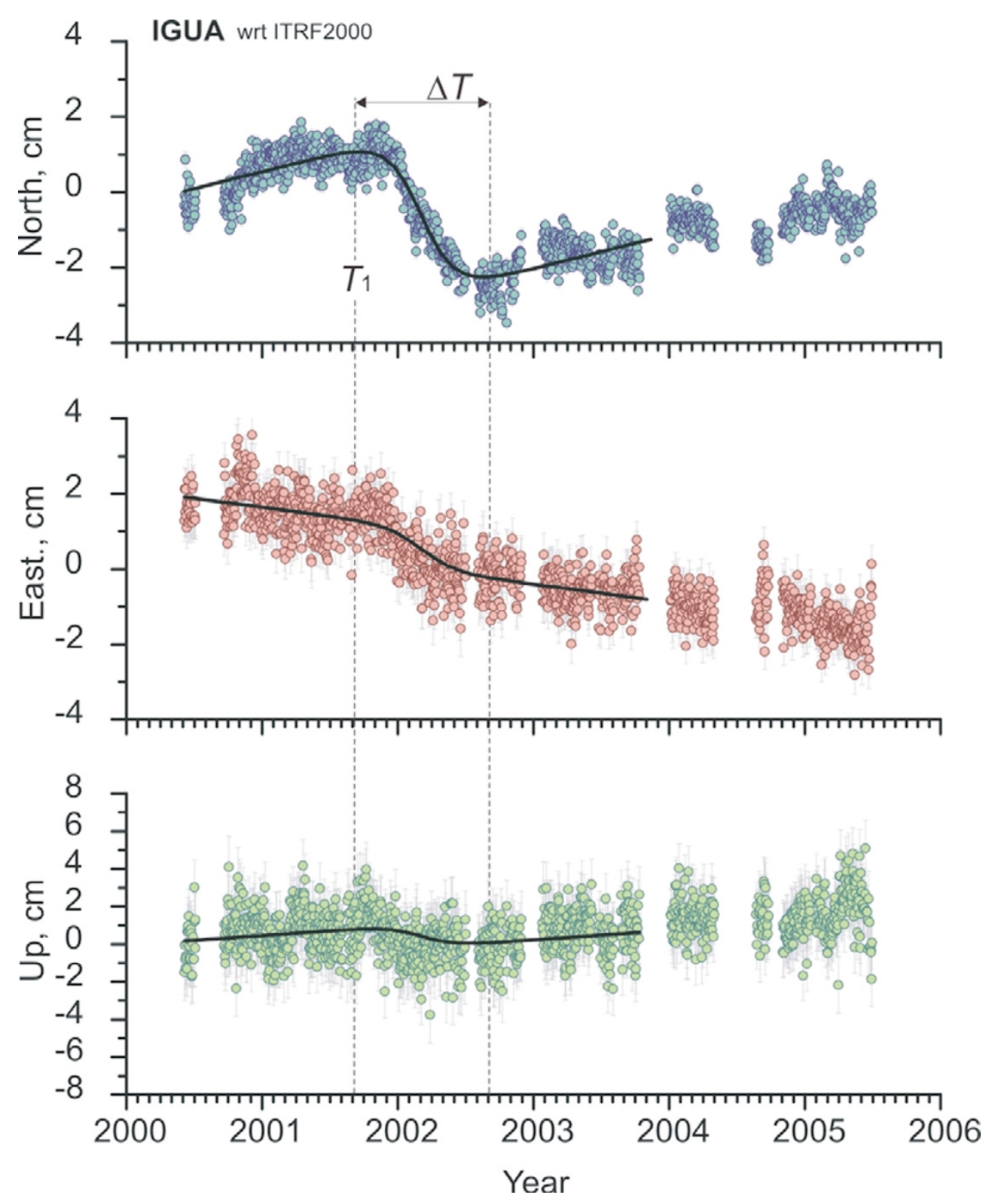

Fig. 4. The example of sigmoid curve (1) best fit to the daily position time series at the IGUA permanent GPS station. The anomalous displacement $U_{N}$, onset, $T_{1}$, and duration time, $\Delta T$, are acquired first by fitting the north component. Then with $T_{1}$ and $\Delta T$ fixed we estimate the amplitudes of the anomalous displacement for the east and vertical components.

recorded the 2001-2002 SQ (Fig. 3). The tilt SQ record shows that the slow event begun about $2 \tau$ earlier then the onset of its most active phase evident in the GPS time series. The LBT record reveals distinct phases of the SQ, which are not obvious in GPS time series. A linear fit method to estimate $V$ and $U$ illustrated in Fig. 3 provides reliable estimates for the onset and duration time when corrected for the earlier arrival of the SQ.

GPS time series and displacements vectors from permanent stations (Figs. 4 and 5C respectively) show that the north component of the SQ displacement is dominant compared with the weak SQ signal in the east component. Furthermore, the east component is noisier and can not easily be used for nonlinear fitting (Eq. (1)) to estimate simultaneously $V_{E}$ and all SQ parameters $\left(t_{0}, \tau\right.$ and $\left.U_{E}\right)$. The fitting scheme applied in this study is based on the postulation that the time limits of the SQ are the same for every compo- nent. We first solve for all SQ parameters fit (Eq. (1)) to the north component and then apply these parameters and estimation of $t_{0}$ and $\tau$, as constraints, to the east and vertical components to obtain $V_{E}, V_{U}$ and $U_{E}, U_{U}$. Figure 4 illustrates an example of such a fit to the IGUA time series. The results of the same analysis applied to the time series from other permanent GPS stations can be found at http://laxdoru.igeofcu.unam.mx/ ivonne/EPS1416.

\section{Propagation Characteristics of the 2001-2002 Silent Earthquake}

At the end of 2001, permanent GPS stations CAYA, IGUA and ACAP recorded the initial phase of a large SQ in Guerrero (Kostoglodov et al., 2003). The station CAYA, located in the middle of the Guerrero seismic gap, experienced the largest vertical and horizontal displacement $(\sim 4.2$ and $\sim 5.2 \mathrm{~cm}$, respectively; Yoshioka et al., 2004) produced 

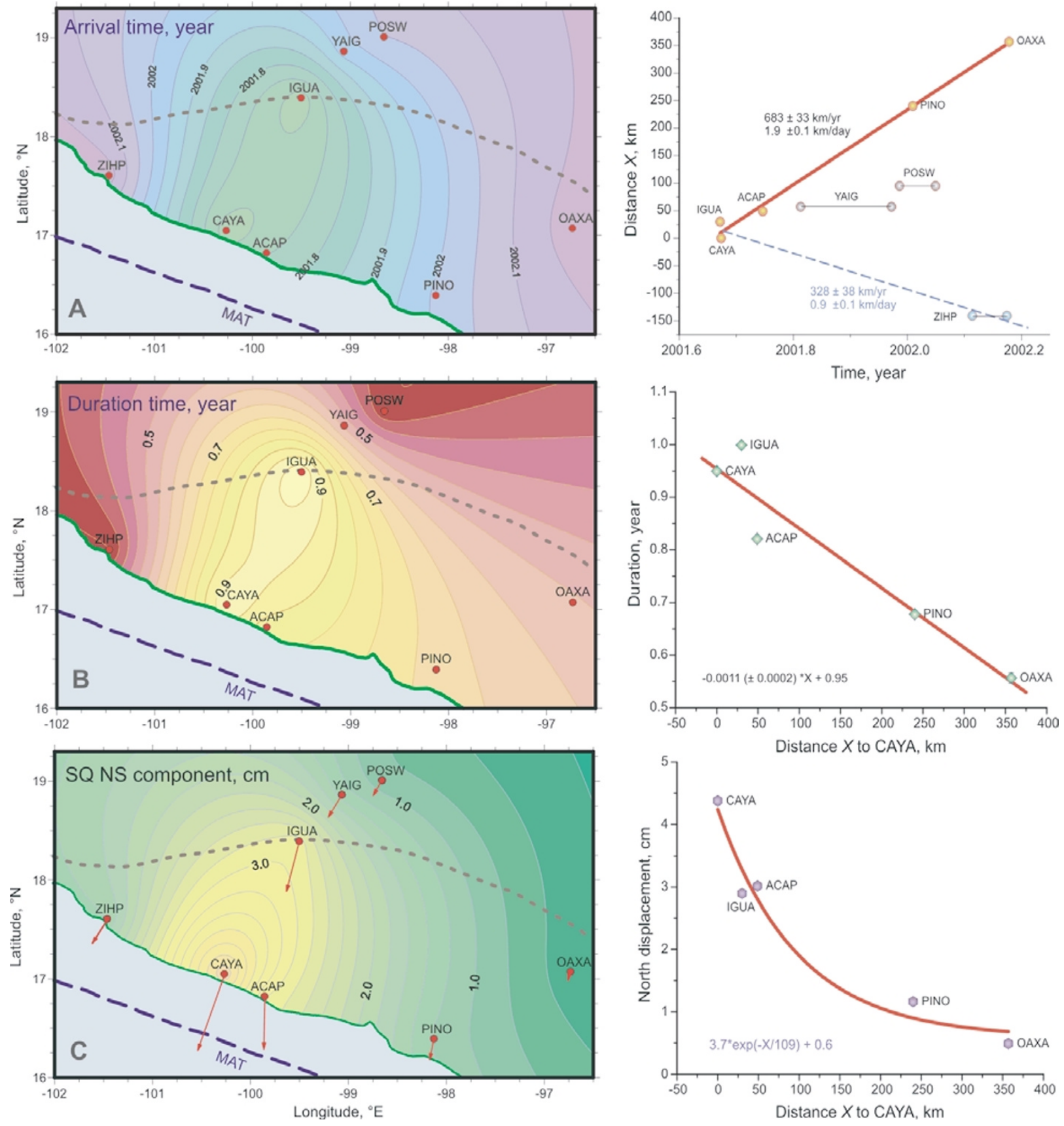

Fig. 5. Propagation parameters of the 2001-2002 silent earthquake. The CAYA station is assumed to be an initial (nucleation) point of the slow event. The dashed line in all maps indicate the $40 \mathrm{~km}$ isodepth contour where the oceanic plate abruptly changes a geometry from subhorizontal to steep subduction. MAT, Middle America trench. A. The SQ onset time map and the onset vs. distance to CAYA plot. Note that the SQ starts almost simultaneously at CAYA and IGUA. B. The map and the SQ anomalous displacement duration as a function of distance. C. Attenuation of the north displacement amplitude map and the attenuation curve. Vectors are the displacements of the permanent GPS stations during the 2001-2002 silent earthquakes. The north component of the displacement is dominant.

by this silent earthquake and this station was the closest to the "epicenter". Other permanent GPS stations detected a change from the steady state inter-event motion to the slow slip rebound motion some time (up to $\sim 6$ months) later than the CAYA and IGUA stations (Fig. 2).

The propagation of the 2001-2002 SQ is determined by the initial time, duration and attenuation of the anomalous displacement at each permanent GPS station. These parameters (estimated by the fitting procedure described in the previous section) are presented in Figure 5 in the form of maps and functions of the along-coast distance to the CAYA

\section{GPS station.}

The propagation rate $\left(V_{P}\right)$ of the SQ crustal deformation is notably anisotropic (Fig. 5A), with the $V_{P}=1.9 \pm 0.1$ $\mathrm{km} /$ day in the southeast direction, along the coastline and trench, and $V_{P}=0.9 \pm 0.1 \mathrm{~km} /$ day towards the northwest along the coast. Considering the SQ displacement on the profile normal to the coast line, the CAYA and IGUA stations (separated $\sim 170 \mathrm{~km}$ ) registered the earliest SQ onset almost simultaneously, whereas at the YAIG and POSW stations (farther to the northeast and on the same profile of CAYA and IGUA) the speed is $V_{P} \approx 0.4 \mathrm{~km} /$ day. The phys- 


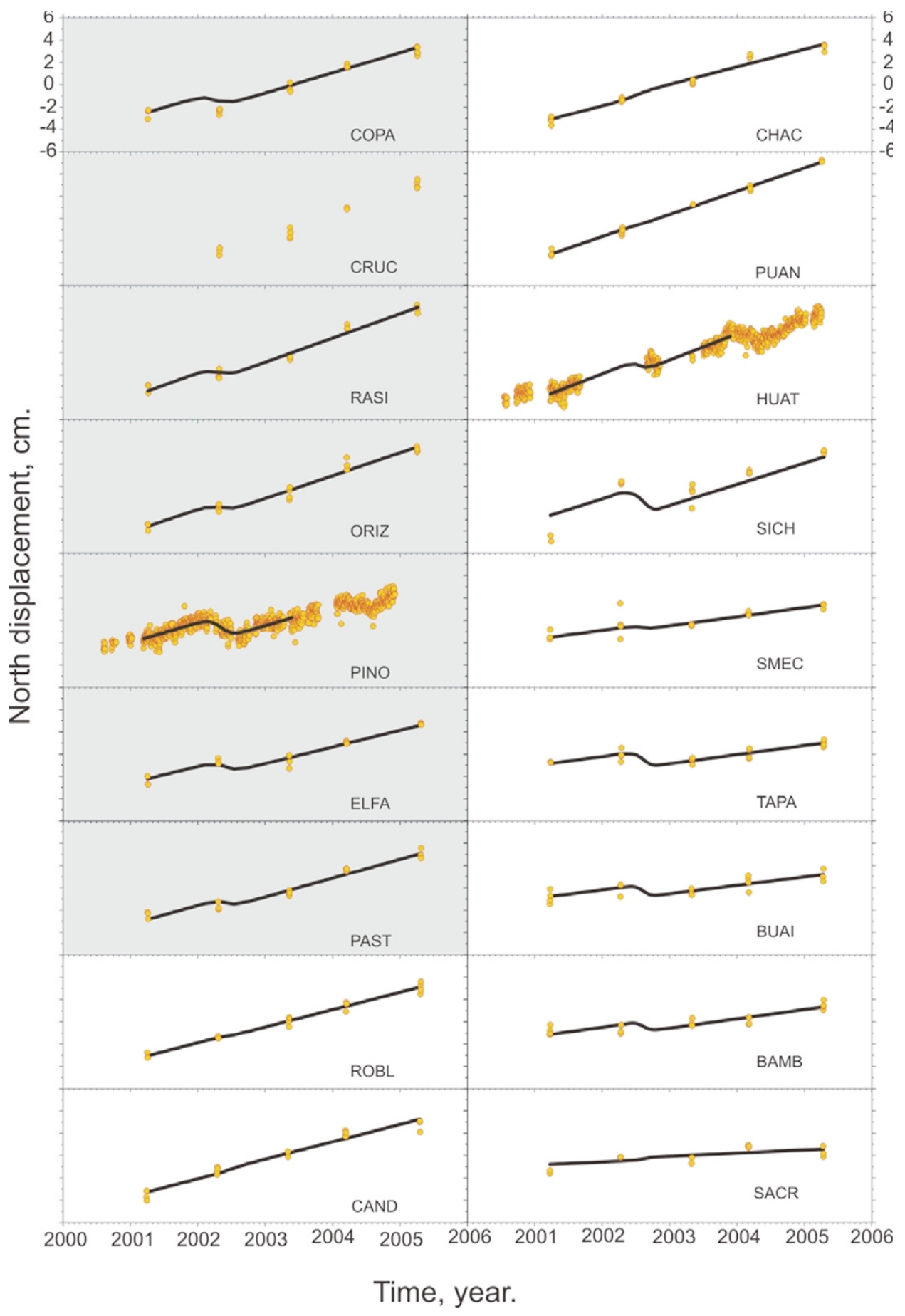

Fig. 6. Modeling of the 2001-2002 SQ north displacements at the campaign GPS sites and PINO, HUAT permanent GPS stations. The SQ displacement and inter-event velocity estimates are obtained by fitting the data with a sigmoid-shape signal. The signal has the constrained onset and duration (except for PINO) calculated form the SQ propagation relations. Shaded charts correspond to the sites where the 2001-2002 SQ could be so far traced. In the area between ROBL and PUAN the modeled SQ displacement signal is insignificant. West of PUAN a hypothetical slow displacement signal may arise from a distinct SQ probably triggered by the preceding main 2001-2002 slow slip.

ical mechanism of the SQ propagation is still unclear, but it is notable that the CAYA and IGUA stations are located over the sub-horizontal section of plate contact, whereas the YAIG and POSW stations are located on the NOAM plate over the mantle wedge (Fig. 5, isodepth contour of -40 $\mathrm{km})$.

Only the SQ propagation towards the southeast along the coast is relevant for this study, provided that the propagation rate is anisotropic. For the estimation of the duration and attenuation of anomalous SQ displacement we only accounted for the stations located along the direction of propagation. The duration of the aseismic slip (Fig. 5B) decreases almost linearly with the distance following:

$$
\Delta T=0.95-0.0011 X,
$$

where distance $X$ is in $\mathrm{km}$, and $\Delta T$ is in years. At a distance of $X \approx 360 \mathrm{~km}$ between the CAYA and OAXA stations the duration decreases from $\sim 11.4$ to 6.7 months. It is 


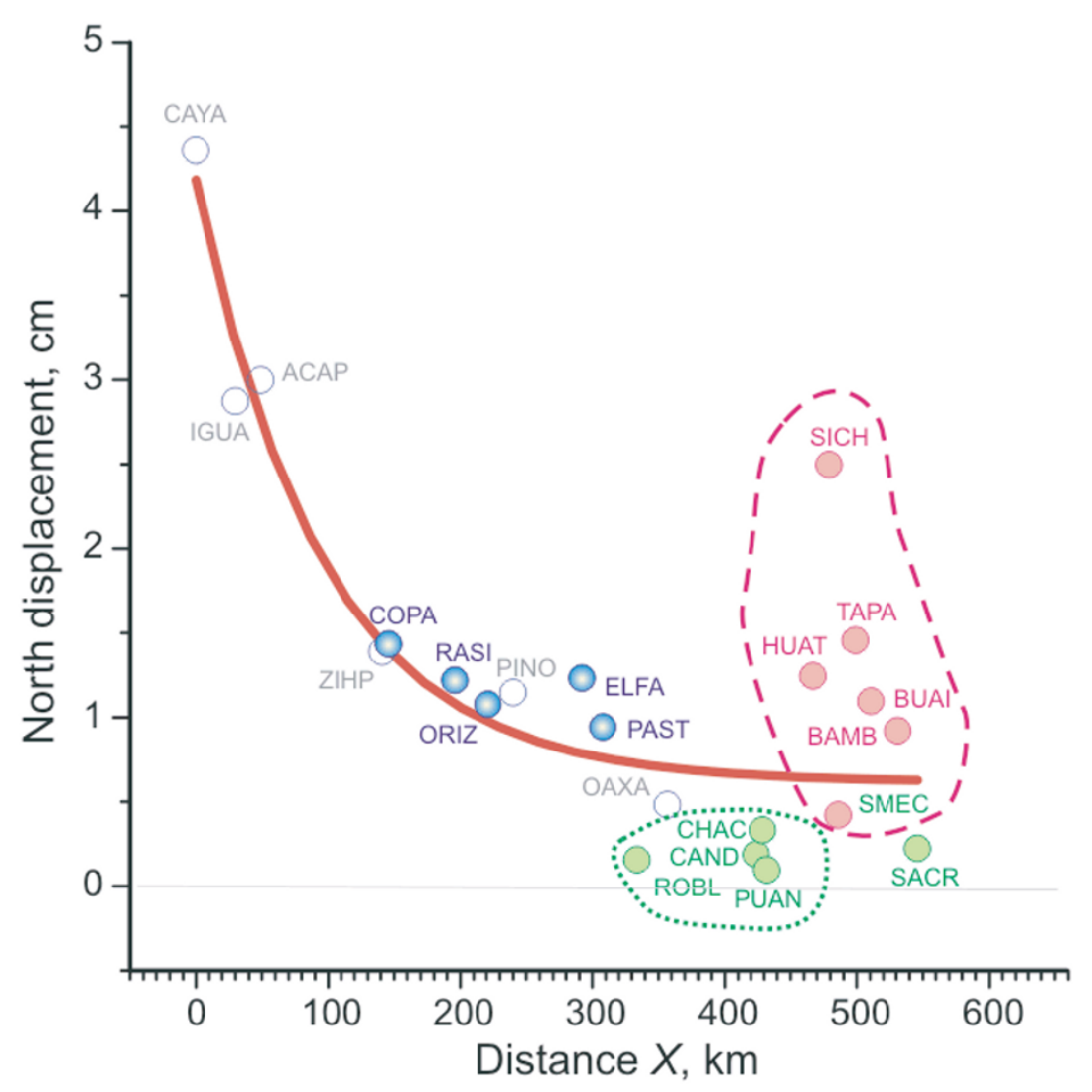

Fig. 7. Comparison between the SQ north displacement amplitudes, $U_{N}$, derived by fitting the sigmoid signal (1) to the campaign GPS time series and the attenuation curve, $U_{N}=f(X)$, approximating $U_{N}$ for the permanent GPS (open circles). Dark (blue) circles are $U_{N}$ for the campaign sites where the SQ anomalous deformation can be tracked. Filled circles enveloped with a pointed curve are the campaign sites in the central Oaxaca where the SQ ceased. Dashed curve enclose the sites where the secondary SQ probably developed. The $U_{N}$ at the SACR site is practically negligible.

unexpected that $\Delta T$ at IGUA station is about 12 months, a longer period than the duration at CAYA station.

The geometric lateral (along the coastline) attenuation of the displacement $\left(U_{N}\right)$ towards the southeast can be approximated by an exponential function of $X$ (Fig. 5C). The amplitude of slow slip displacement is then:

$$
U_{N}=3.7 e^{-X / 109}+0.6,
$$

which means the SQ signal decreases by almost 6 times at a distance of $\sim 400 \mathrm{~km}$.

\section{Silent Earthquake Propagation from Cam- paign GPS Data from Oaxaca}

The 2001-2002 silent earthquake was still ongoing during the March 2002 GPS campaign in Oaxaca. At that time, the permanent CAYA and ACAP stations had already recorded over half of the slow event period. At the permanent PINO station, located about $240 \mathrm{~km}$ southeast from the CAYA station, the slow event had just started. Permanent farther stations did not record the slow event at the time of the 2002 campaign. The ZIHU and OAXA stations were the last permanent stations to be perturbed by aseismic slip deformation, after the completion of the 2002 campaign in Oaxaca (Fig. 2). Thus the data from the campaign GPS sites in Oaxaca should combine the inter-slip steady state motion for the 2001-2005 and the effect of 2001-2002 SQ anomalous deformation if the slow slip reached those sites.
In order to verify the propagation of the SQ at the campaign sites we assume that the anomalous deformation signal progressed towards the southeast, along the coast, with an estimated propagation rate that satisfies Eqs. (2) and (3). According to this, we can calculate the constraints $t_{0}$ and $\tau$ from $T_{1}$ and $\Delta T$ for each campaign site located at a distance $X$ from the CAYA station. Then, by fitting Eq. (1) with fixed $t_{0}$ and $\tau$ to the five data sets with the north component of the campaign time series we may obtain estimates of $U_{N}$. The results of this procedure are shown in Fig. 6.

The modeled north component of the SQ displacement in the Guerrero-Oaxaca boundary area (sites COPA to PAST shaded charts in Fig. 6) is consistent with the $U_{N}$ vs. $X$ relation (Eq. (3)) for the permanent GPS stations (Fig. 7). This agrees with our assumptions about SQ propagation, at least up to PAST site.

For the central Oaxaca GPS sites, ROBL to PUAN, the $U_{N}$ values are negligible and do not match Eq. (3), which indicates that the 2001-2002 SQ likely ceased in this area. Cabral et al. (2003) by a preliminary report of the velocity measurements at a different local GPS network, concentrated between the ROBL and PUAN sites, reported, in agreement with our observations no evidence of the 20012002 SQ in this region.

The modeled propagation of deformation in southeastern Oaxaca (farther to the east from PUAN) does not fit the GPS data. At the eastward station (SACR) (Fig. 1), the mod- 


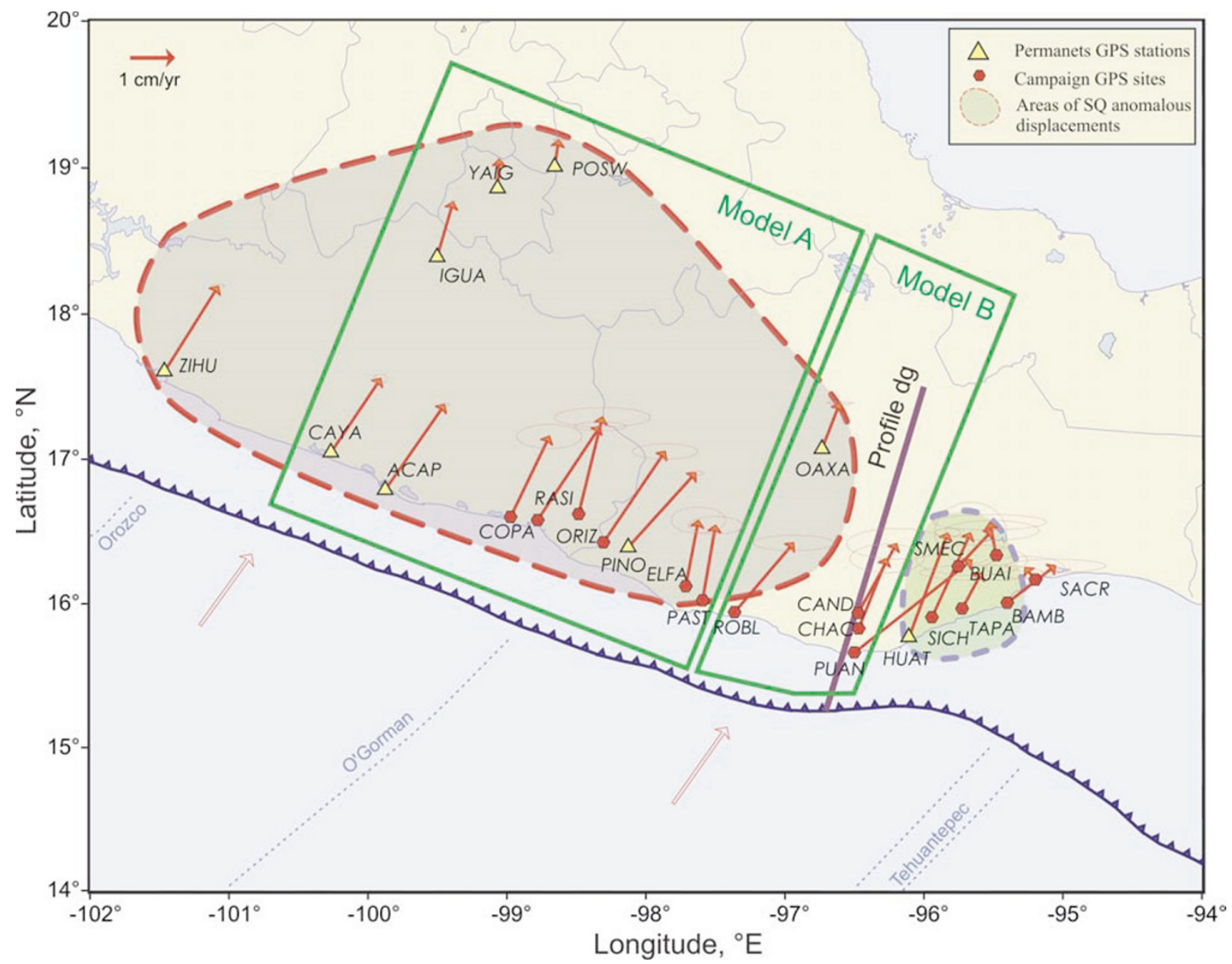

Fig. 8. Inter-event steady state velocity vectors (solid arrows) at the campaign sites and permanent GPS stations during the pre- and post-2001-2002 SQ epochs. Ellipses denote $2 \sigma$ formal velocity errors. The propagation region of the SQ is shown by a large shaded area with a dashed contour line. Small shaded area indicates the size of probable secondary SQ. The annotated open rectangle and rectangle-like outline delimit the GPS sites used for the dislocation modeling. Open arrows indicate directions of the convergence between the Cocos and North American plates (DeMets et al., 1994). The location of the gravimetric profile (Fig. 9) is shown by the solid line annotated as "Profile dg".

eled anomalous displacement emerges again but the $U_{N}$ estimates definitely exceed the level predicted by the attenuation relation (Eq. (3)) (Figs. 6, 7). This observation does not agree with a simple slow propagation of (southward) deformation model and suggests that a separate SQ occurred, probably triggered by the large 2001-2002 SQ. Occupation GPS data and the incomplete time series in HUAT permanent GPS station are not sufficient to make any feasible inference of the arrival time and duration of this SSE. Nonetheless, the modeled anomalous displacements seem to be reliable when examined in Fig. 6. The secondary SQ (if it is not a modeling artifact) originated in the transition zone between the sub-horizontal subduction plate interface in Guerrero-Oaxaca and the normal steep subduction interface geometry in Chiapas, and was possibly related with this transition zone.

The modeling of the SQ anomalous displacements in east components $\left(U_{E}\right)$ of occupation time series is not as satisfactory as for the $U_{N}$ component due to the smaller magnitude of the deformation signal and higher scatter of the data.

\section{Configuration of the Plate Interface}

The configuration of the interplate contact is an important constraint for the inter-event coupling model. Based on the rough estimates of the subducted plate geometry (Pardo and Suárez, 1995; Torres-Zamudio, 2002) we distinguish two areas with distinct geometries of the plate interface: (1) Central Oaxaca, similar to Guerrero, and (2) Southeastern Oaxaca and the Tehuantepec Isthmus, which is a transition between a sub-horizontal subduction and a "common" steep subduction in Chiapas. The boundary between the two areas strikes SW-NE, approximately $96^{\circ} \mathrm{W}$ (flanked by Puerto Angel and Huatulco, PUAN and HUAT; Fig. 1).

A combined 2D gravity and magnetic model as well as the intra-slab seismicity are used to constrain the slab geometry in the Central Oaxaca area (Fig. 9). The profile orientation is shown in Fig. 8. The gravity data were obtained onshore by De la Fuente et al. (1994) and offshore by means of the GEODAS v4.1 (2002). The magnetic anomalies are MAGSAT data reduced to the pole (RP) (Hinze et al., 1982). The configuration of the slab used in the present modeling is similar to the gravity models of Guerrero ob- 

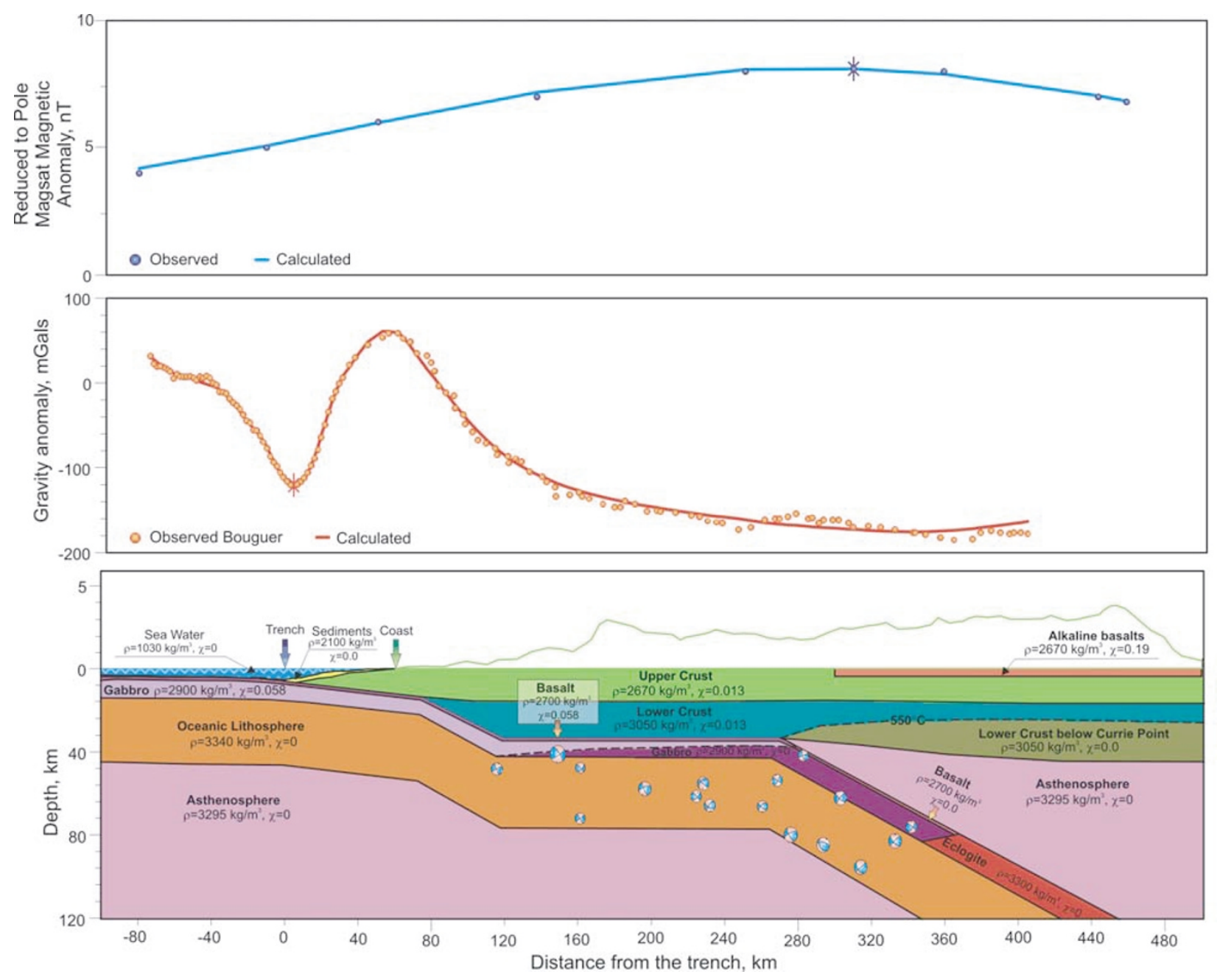

Fig. 9. Gravity and magnetic anomalies modeling used to constrain the interplate contact geometry in the Central Oaxaca area. Position of the profile is shown in Fig. 8 (Profile dg). For other explanations see text: Configuration of the plate interface.

tained by Kostoglodov et al. (1996). For the sake of consistency we used the same densities: $3295 \mathrm{~kg} / \mathrm{m}^{3}$ for the upper mantle, 2700 and $2900 \mathrm{~kg} / \mathrm{m}^{3}$ for the upper part of the oceanic plate (basalt and gabbro), $3340 \mathrm{~kg} / \mathrm{m}^{3}$ for the oceanic lithosphere, $2670 \mathrm{~kg} / \mathrm{m}^{3}$ for the continental upper crust, and $3050 \mathrm{~kg} / \mathrm{m}^{3}$ for the continental lower crust. We also consider a depth for the transition from basalts to eclogites at $\sim 70 \mathrm{~km}$, which is consistent with the recent thermal and metamorphic models for Guerrero (Manea et al., 2004). We used a density of $3300 \mathrm{~kg} / \mathrm{m}^{3}$ for eclogites.

The shape of the MAGSAT magnetic anomaly over the subduction zone is attributed to the magnetization contrast between the cold subducting oceanic crust (below Curie point, $\sim 550^{\circ} \mathrm{C}$ ) and surrounding non-magnetic mantle (Clark et al., 1985; Vasicek et al., 1988). The setting of the $550^{\circ} \mathrm{C}$ Curie isotherm is consistent with recent thermal models of the Guerrero subduction zone (Manea et al., 2004). The RP MAGSAT anomaly over Oaxaca subduction zone at the altitude of $350 \mathrm{~km}$ is induced by a constant magnetic field of 60,000 nT (Hinze et al., 1982). The following values for magnetic susceptibilities are used (see Fig. 9): 0.058 SI for the oceanic slab, and 0.013 SI for the continental crust (Nagata, 1969; Thomas, 1984). To fit the magnetic model with the observed anomaly we also included the ef- fect of the Tuxtla alkaline basalts, using a $3 \mathrm{~km}$ thick layer with a high magnetic susceptibility of 0.19 SI. This minor contribution from the Tuxtla volcanic province was considered by Vasicek et al. (1988) in order to fit the 3D magnetic model over Oaxaca with a maximum magnetic field of $\sim 10$ nT corresponding to the MAGSAT scalar anomaly.

The intraslab seismicity with magnitude $M_{W}$ over 5 is shown in Fig. 9 as additional constraints to the model. The distribution of hypocenters is consistent with the flat subhorizontal section of the subducted slab, and also suggest that the slab dips $\sim 20^{\circ}$ into the asthenosphere.

\section{Elastic Dislocation Models}

Elastic energy of accumulated deformation due to a partially coupled or fully locked interface between subducting and overriding tectonic plates could rebound as large subduction thrust earthquakes and, to some extent, gradually released by silent earthquakes. Consequently, the coupling ratio should vary depending on the stage of the seismic cycle and the influence of SQs. It is essential to appraise the maximum value of coupling ratio that is achieved during inter-event steady state phase of plate interaction.

Since the subduction geometry changes significantly from Central to Eastern Oaxaca and probably two distinct 

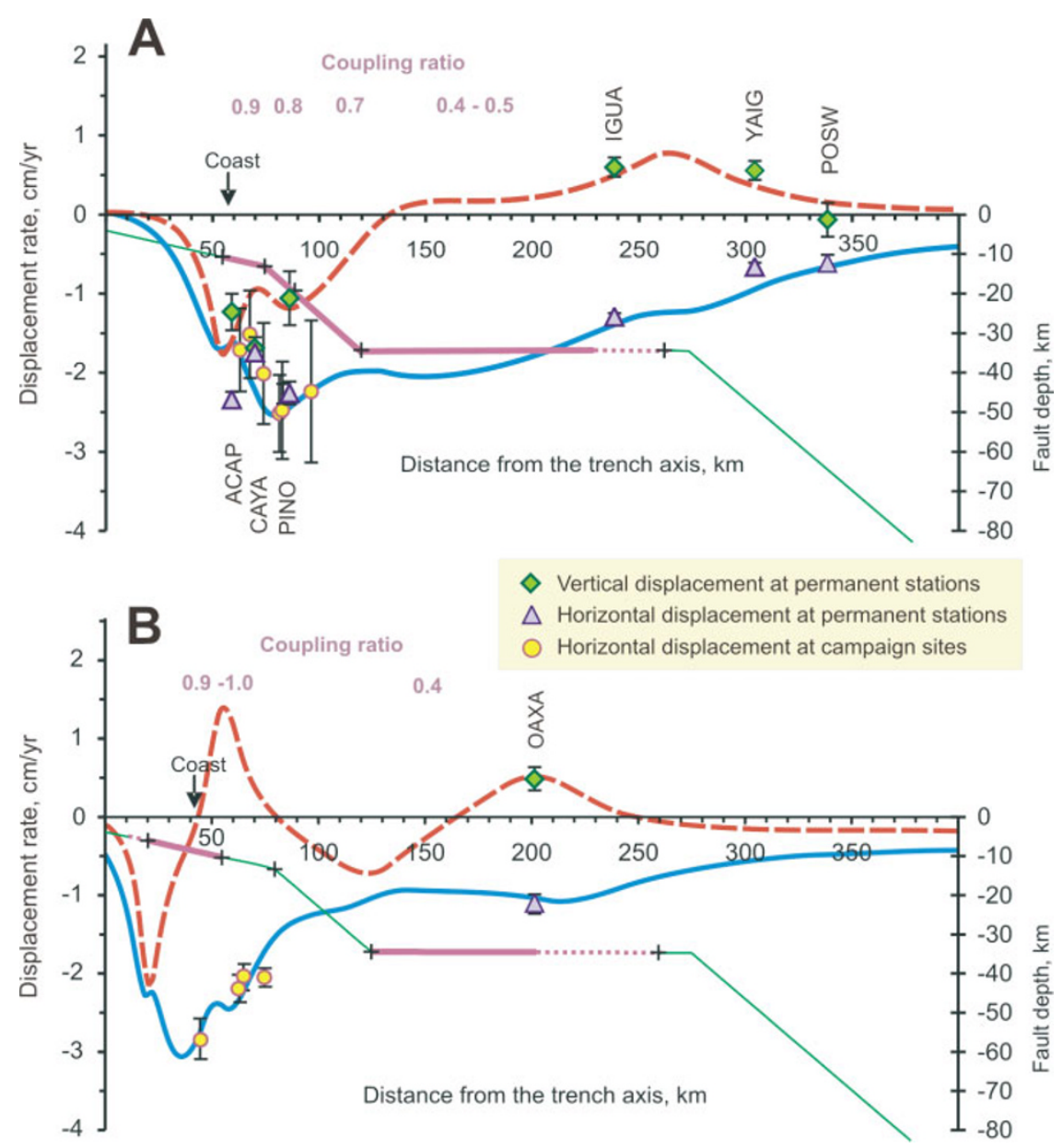

Fig. 10. Elastic half space dislocation models for the steady state inter-event epochs before and after the 2001-2002 SQ. Dashed (red) and solid (blue) curves are the modeled uplift and horizontal (negative is compressional) displacement rates, correspondingly. Thick line segments on the plate interface represent a coupled zone annotated with the degree of interplate coupling. The modeled data are shown as circles (campaign sites) and triangles (permanent GPS) for horizontal and diamonds for vertical velocity components. A. Eastern Guerrero-Western Oaxaca (Model A area in Fig. 8). B. Central Oaxaca (Model B area in Fig. 8). Plate interface geometry is constrained by the gravity anomalies modeling (Fig. 9) for the Profile dg shown in Fig. 8. The observed campaign uplift rates have large errors and are not used for modeling. Note a large free slipping segment right downdip of the seismogenic locked zone, which is probably responsible for the 2001-2002 SQ cease in Central Oaxaca.

SQs have occurred in these areas, it would be necessary to consider two different coupling models, one for each region. The eastern Oaxaca subduction segment has a transitional (from sub-horizontal to steep subduction) 3D geometry and requires more data from a larger number of GPS sites to be modeled adequately. In this study we apply a simple 2D elastic dislocation model of Savage (1983) to estimate the steady state coupling only in the subduction segment extending from Guerrero to Central Oaxaca, where the plate interface is subhorizontal and it can be fairly well represented by $2 \mathrm{D}$ profiles.

The vectors of inter-event velocities calculated by fitting GPS time series with function (1) are presented in Fig. 8. It is reasonable to model the velocities separately in two neighboring segments (Fig. 8): A-a broad boundary zone between Guerrero and Oaxaca where the 20012002 SQ anomalous displacement was recorded, and BCentral Oaxaca zone, between the PAST and HUAT GPS sites where the SQ displacement was absent. Model A (Fig. 10) is rather similar to the dislocation model for Guerrero (Kostoglodov et al., 2003). In previous studies (i.e. Iglesias et al., 2004; Kostoglodov et al., 2003; Yoshioka et al., 2004), the GPS sites velocities were estimated for only pre-2001-2002 SQ steady state motion at the profile ACAP-YAIG. In the present model A, the velocities correspond to the average steady state motion during pre- and post-SQ epochs, and the data set encompasses also permanent and occupation GPS sites in western Oaxaca (Fig. 8). The plate interface geometry is adopted from Kostoglodov et al., 1996. The model fits fairly well the observed interevent displacement rates when the plate interface has a major coupling ratio ${ }^{1}, \kappa=0.8-0.9$, on the $35 \mathrm{~km}$ wide seismogenic zone, which starts at $\sim 55 \mathrm{~km}$ from the trench. $\kappa$ decreases from 0.7 to $0.4-0.5$ downdip from the seismogenic patch, along the broad transition zone (Fig. 10A). This partially coupled zone extends from $90 \mathrm{~km}$ up to $\sim 210-260$ $\mathrm{km}$ inland from the trench and, it is where the slow slip occurred during the SQ (Kostoglodov et al., 2003; Iglesias et al., 2004).

${ }^{1}$ Coupling ratio is defined in a kinematics sense (Wang and Dixon, 2004) as the ratio of back-slip rate estimated by the dislocation modeling to the convergence rate calculated from NUVEL 1A plate motion model (DeMets et al., 1994). 
In model B (Figs. 8 and 10B) the plate interface geometry is determined from the gravity modeling described in the previous section (Fig. 9). Forward models that fit the observed displacement rates (Fig. 10B) require a shallow seismogenic coupled zone, $\kappa=0.9-1.0$, located between $5-20 \mathrm{~km}$ and $55 \mathrm{~km}$ from the trench. Farther inland and deeper, a partially coupled transition zone, $\kappa=0.4$, extends from $120 \mathrm{~km}$ to approximately $200-250 \mathrm{~km}$. The rest of the plate interface slips freely including the patch located between $55 \mathrm{~km}$ and $120 \mathrm{~km}$ from the trench. Although the forward modeling does not provide a unique solution it is not possible to fit the observed displacement rates without this uncoupled patch. The free slipping patch is not capable to accumulate strain and therefore is unable to generate a slow slip. In contrary, the SQ may occur on the partially locked region between 120 and $\sim 200 \mathrm{~km}$ from the trench.

One more permanent GPS station installed somewhere halfway between the coast and Oaxaca City (OAXA in Fig. 1) would provide vertical deformation rate data crucial to verify model $\mathrm{B}$.

\section{Discussion and Conclusions}

The 2001-2002 silent earthquake affected a very large region in Central Mexico. The noticeable anomalous displacements produced by this SQ were observed in a $350 \mathrm{~km}$ area along the Pacific coast and about $250 \mathrm{~km}$ inland from the coast. This long-distance effect is attributed to the subhorizontal configuration of the subduction plate interface, which is partially coupled on its broad transition zone from the seismogenic locking to free slipping. The 2001-2002 GPS position time series provide an unique opportunity to investigate the propagation characteristics of large SQ, such as onset time, duration, and attenuation of the anomalous SQ deformation.

The analysis of the LBT data shows that the duration time of 2001-2002 SQ displacement recorded by the ACAP permanent GPS station is about two times longer than the most active phase of the anomalous displacement. This observation required a reevaluation of onset times at all GPS stations of the network "Simologia-UNAM". The new onset times reveal a strong anisotropy in the SQ propagation. The SQ displacement started almost simultaneously at the CAYA and IGUA stations, positions that lie on a perpendicular line to the Middle America Trench close to the center of the Guerrero seismic gap (Fig. 1). Then, the anomalous displacement propagated with $V_{p}=1.9 \pm 0.1 \mathrm{~km} /$ day toward the southeast along the Pacific coast of Mexico. In the northwest direction, from CAYA to ZIHU, $V_{p} \approx 0.9$ $\mathrm{km} /$ day. The lowest $V_{p} \approx 0.4 \mathrm{~km} /$ day toward the northeast, between the IGUA and POSW stations, correlates with the abrupt change of the subducted plate dip angle. The SQ anomalous displacement reveals the exponential geometric attenuation of its north component and a linear inverse relation between the SQ duration and the propagation distance.

We used five yearly survey observations (2001-2005) of campaign GPS sites in Guerrero and Oaxaca to trace the SQ propagation toward the southeast, along the Pacific coast of Mexico. The tracking method consisted of a comparison of predicted and estimated amplitudes of anomalous SQ deformation at each campaign GPS site. The amplitudes were estimated assuming that the SQ step-like deformation signal spreads all over the coastline area in accordance with the empirical propagation relations obtained from the continuous GPS data. The onset and duration calculated from these relations constrain the time limits of the sigmoid signal.

The estimated anomalous amplitudes of deformation in central Oaxaca are small; thus the SQ did not continue to propagate through this region. Unexpectedly, the anomalous amplitudes are noticeably higher than the empirical prediction in the southwestern part of Oaxaca. We speculate that the 2001-2002 silent earthquake propagated from Guerrero into the western Oaxaca and gradually ceased before $\sim 95.7^{\circ} \mathrm{E}$. There are no deformation signatures of the SQ in the central Oaxaca coastal area between $95.7^{\circ} \mathrm{E}$ and $96.5^{\circ} \mathrm{E}$. The estimated anomalous displacements in southeastern Oaxaca do not provide sufficient evidence to confirm the occurrence of another SQ. Nevertheless, we cannot discard the possibility that the 2001-2002 SQ triggered a small $\mathrm{SQ}$.

To examine a probable difference in the inter-event coupling structure between the areas where the 2001-2002 SQ propagated and ceased we performed a simple 2D dislocation modeling using the GPS derived velocities for the preand post SQ steady state motion. The average model for the western Guerrero-eastern Oaxaca region determines a 120$170 \mathrm{~km}$ wide partially coupled zone located just downdip from the seismogenic highly coupled plate interface patch. The 2001-2002 slow slip developed in this transition zone. The steady-state velocities modeled in the central Oaxaca area reveals a $\sim 65 \mathrm{~km}$ wide free slipping gap, which separates a shallow seismogenic zone and a partially coupled transition zone. This uncoupled gap on the plate interface may act as a barrier for the SQ southeastward propagation.

A denser GPS network of permanent stations, with a distance between stations less then $40 \mathrm{~km}$, particularly in the coastal area, is needed for more detailed studies of silent earthquakes and variation of interplate coupling along the subduction zone of Mexico. The long baseline tiltmeters are more sensitive than GPS to the onset and intermediate phases of SQs. A combination of these two techniques would be very promising for future studies of slow slip propagation and its triggering effect.

Acknowledgments. This study was supported by G25842-T, 37293-T CONACyT and IN104599 PAPIIT grants. The authors thank Guillermo Lara, Cristina Bancora, Patricia Julio Miranda, Wallis Hutton and Javier Alvarado for their help in the survey campaigns. The POSW GPS station is maintained by the CARDI Lab at the Instituto de Geofisica, UNAM, and the data are in the public access at the UNAVCO data base (http://archive.unavco.org/ query/pss). NSF EAR-0125618 provided funds to the University of Colorado to partially support Guerrero measurements. We thank Carles Canet and Antoni Camprubi for their help in reviewing the manuscript. The authors appreciate valuable comments from Dr. Takeshi Sagiya, Dr. Laura Wallace and Dr. Teruyuki Kato which helped to improve this manuscript.

\section{References}

Altamimi, Z., P. Sillard, and C. Boucher, ITRF2000: A new release of the International Terrestrial Reference Frame for earth science applications, J. Geophys. Res., 107(B10), 2214, doi:10.1029/2001JB000561, 2002.

Anderson, J., R. Quaas, S. Singh, J. Espinosa, A. Jiménez, J. Lermo, J. Cuenca, F. Sánchez-Sesma, R. Meli, M. Ordaz, S. Alcocer, B. López, 
L. Alcántara, E. Mena, and C. Javier, The Copala, Guerrero, Mexico, Earthquake of September 14, $1995\left(M_{W}=7.4\right)$ : A Preliminary Report, Seism. Res. Lett., SSA, 66(6), 11-39, 1995.

Beavan, J., L. Wallace, and T. Hurst, Observation of an aseismic deformation episode above the northern Hikurangi margin subduction zone, New Zealand, EGS Geophysical Research Abstracts, 5, 04839, 2003.

Boucher, C., Z. Altamimi, and P. Sillard, The 2000 International Terrestrial Reference Frame (ITRF2000), Technical Note 31, IERS, 2003.

Bravo, H., C. J. Rebollar, A. Uribe, and O. Jimenez, Geometry and state of stress of the Wadati-Benioff zone in the Gulf of Tehuantepec, Mexico, J. Geophys. Res., 109, B04307, doi:10.1029/2003JB002854, 2004.

Cabral, E., F. Correa Mora, B. Marquez Azúa, and C. DeMets, A GPS study of the subduction interface beneath Oaxaca, Mexico, GEOS, Union Geofísica Mexicana, 23, 182, 2003.

Clark, S. C., H. Frey, and H. H. Thomas, Satellite magnetic anomalies over subduction zones: the Aleutian Arc anomaly, Geophys. Res. Lett., 12, 41-44, 1985

De la Fuente Duch, M. F., M. Mena, and C. L. V. Aiken, Cartas Gravimétricas de la Republica Mexicana. I. Carta de anomalía Bouguer, Instituto de Geofísica, UNAM, 1994.

DeMets, C., R. Gordon, D. Argus, and S. Stein, Effect of recent revisions to the geomagnetic time-scale on estimate of current plate motions, Geophys. Res. Lett., 21, 2191-2194, 1994.

Douglas, A., J. Beavan, L. Wallace, and J. Townend, Slow slip on the northern Hikurangi subduction interface,New Zealand, Geophys. Res. Lett., 32, 2005L16305, doi:10.1029/2005GL023607, 2005.

Dragert, H., K. Wang, and T. S. James, A Silent Slip Event on the Deeper Cascadia Subduction Interface, Science, 292, 1525-1528, 2001.

Freymueller, J. T., S. Hreinsdottir, C. Zweck, and P. J. Haeussler, The 1998-2002 deep megathrust slip event, Alaska, AGU 2002 Fall Meeting, G61A-0972, 2002.

GEODAS vs. 4.1, Marine Trackline Geophysics, U.S. Department of Commerce, National Oceanic and Atmospheric Administration, 2002.

Heflin, M., W. Beriger, G. Blewitt, A. P. Freedman, K. Hurst, S. Lichten, J. Lindqwister, Y. Vigue, F. Webb, T. P. Yunck, and J. Zumberge, Global geodesy using GPS without fiducial sites, Geophys. Res. Lett., 19, 131134, 1992.

Hinze, W. J., R. R. B. Von Frese, M. B. Longacre, and L. W. Braile, Regional magnetic and gravity anomalies of South America, Geophys. Res. Lett., 9, 314-317, 1982.

Hirose, H., K. Hirahara, F. Kimata, N. Fujii, and S. Miyazaki, A slow thrust slip event following the two 1996 Hyuganada earthquakes beneath the Bungo Channel, southwest Japan, Geophys. Res. Lett., 26, 3237-3240, 1999.

Iglesias, A., S. K. Singh, A. R. Lowry, M. Santoyo, V. Kostoglodov, K. M. Larson, S. I. Franco-Sánchez, and T. Mikumo, The silent earthquake of 2002 in the Guerrero seismic gap, Mexico $\left(M_{W}=7.4\right)$ : inversion of slip on the plate interface and some implications, Geofisica Int., $\mathbf{4 3}$, 309-317, 2004.

Kawasaki, I., Silent earthquakes occurring in a stable-unstable transition zone and implications for earthquake prediction, Earth Planets Space, 56, 813-821, 2004.

Kostoglodov, V. and W. Bandy, Seismotectonic constraints on the convergence rate between the Rivera and North American plates, J. Geophys. Res., 100, 17,977-17,989, 1995.

Kostoglodov, V. and L. Ponce, Relationship between subduction and seismicity in the Mexican part of the Middle America Trench, J. Geophys. Res., 99, 729-742, 1994.

Kostoglodov, V., W. Bandy, J. Domínguez, and M. Mena, Gravity and seismicity over the Guerrero seismic gap, Mexico, Geophys. Res. Lett., 23, 3385-3388, 1996.

Kostoglodov, V., R. Bilham, J. A. Santiago, V. Manea, M. Manea, and V. R. Hernández, Long-baseline fluid tiltmeter for seismotectonic studies of Mexican subduction zone, Geofísica Internacional, 41(1), 11-25, 2002.

Kostoglodov, V., S. K. Singh, J. A. Santiago, S. I. Franco, K. M. Larson, A. R. Lowry, and R. Bilham, A large silent earthquake in the Guerrero seismic gap, Mexico, Geophys. Res. Lett., 30, 1807, 2003.

Larson, K., V. Kostoglodov, A. Lowry, W. Hutton, O. Sanchez, K. Hudnut, and G. Suarez, Crustal Deformation Measurements in Guerrero, Mexico, J. Geophys. Res., 109(B4), B04409 10.1029/2003JB002843, 2004.

Lichten, S. and J. Border, Strategies for high precision Global Positioning System orbit determination, J. Geophys. Res., 92, 12,751-12,762, 1987.

Lowry, A. R., K. M. Larson, V. Kostoglodov, and R. Bilham, Transient slip on the subduction interface in Guerrero, southern Mexico, Geophys. Res. Lett., 28, 3753-3756, 2001.
Manea, V. C., M. Manea, V. Kostoglodov, C. A. Currie, and G. Sewell, Thermal structure, coupling and metamorphism in the Mexican subduction zone beneath Guerrero, Geophys. J. Int., 158, 775-784, 2004.

Mao, A., C. G. A. Harrison, and T. H. Dixon, Noise in GPS coordinate time series, J. Geophys. Res., 104, 2797-2816, 1999.

Marquez-Azua B. and C. DeMets, Crustal velocity field of Mexico from continuous GPS measurements, 1993 to June 2001: Implications for the neotectonics of Mexico, J. Geophys. Res., 108(B9), B092450 10.1029/ 2002JB002241, 2003.

Melbourne, T. I., W. M. Szeliga, M. M. Miller, and V. M. Santillan, Extent and duration of the 2003 Cascadia slow earthquake, Geophys. Res. Lett., 32, L04301, doi:10.1029/2004GL021790, 2005.

Miller, M. M., T. I. Melbourne, D. J. Johnson, and W. Q. Sumner, Periodic slow earthquakes from the Cascadia subduction zone, Science, 295, 2423, 2002.

Nagata, T., Reduction of geomagnetic data and interpretation of anomalies, in The Earth's Crust and Upper Mantle Geophysical Monograh, edited by P. J. Hart, American Geophysical Union, 13, pp. 391-398, 1969.

Ozawa, S., M. Murakami, M. Kaidzu, T. Tada, T. Sagiya, Y. Hatanaka, H. Yarai, and T. Nishimura, Detection and Monitoring of Ongoing Aseismic Slip in the Tokai Region, Central Japan, Science, 298, 1009-1010, 2002.

Pardo, M. and G. Suárez, Shape of the subducted Rivera and Cocos plates in southern Mexico: Seismic and tectonic implications, J. Geophys. Res., 100, 12357-12373, 1995.

Sagiya, T., Interplate Coupling in the Kanto District, Central Japan, and the Boso Peninsula Silent Earthquake in May 1996, PAGEOPH, 161(1112), 2327-2342, 2004.

Sagiya, T. and S. Ozawa, Anomalous transient deformation and silent earthquakes along the Nankai Trough subduction zones, Seismol. Res. Lett., 73(2), 234-235, 2002.

Savage, J. C., A dislocation model of strain accumulation and release at a subduction zone, J. Geophys. Res., 88, 4984-4996, 1983.

Singh, S. K., J. Havskov, and L. Astiz, Seismic gaps and recurrence periods of large earthquakes along the Mexican subduction zone, Bull. Seism. Soc. Am., 71(3), 827-843, 1981.

Singh, S. K., M. Rodríguez, and L. Esteva, Statistics of small earthquakes and frequency of occurrence of large earthquakes along the Mexican subduction zone, Bull. Seism. Soc. Am., 73(6), 1779-1796, 1983.

Singh, S. K., M. Ordaz, L. Alcantara, N. Shapiro, V. Kostoglodov, J. F. Pacheco, S. Alcocer, C. Gutierrez, R. Quaas, T. Mikumo, E. Ovando, J. Aguirre, D. Almora, J. G. Anderson, M. Ayala, C. Javier, G. Castro, R. Duran, G. Espitia, J. Estrada, E. Guevara, J. Lermo, B. Lopez, O. Lopez, M. Macias, E. Mena, M. Ortega, C. Perez, J. Perez, M. Romo, M. Ramirez, C. Reyes, R. Ruiz, H. Sandoval, M. Torres, E. Vazquez, R. Vazquez, J. M. Velasco, and J. Ylizaturri, The Oaxaca earthquake of 30 September $1999\left(M_{W}=7.5\right)$; a normal-faulting event in the subducted Cocos plate, Seism. Res. Lett., 71, 67-79, 2000.

Suarez, G., T. Monfret, G. Wittlinger, and C. David, Geometry of subduction and depth of the seismogenic zone in the Guerrero gap, Mexico, Nature, 345, 336-338, 1990.

Thomas, H. H., Petrologic model of the northern Mississippi Embayment based on satellite magnetic and ground based geophysical data, Earth Planet. Sci. Lett., 70, 115-120, 1984.

Torres-Zamudio, A., El campo gravimétrico y la estructura de la zona de subducción en Oaxaca, Mexico, B.S.-Thesis, Escuela Superior de Ingeniería y Arquitectura, Instituto Politécnico Nacional, pp. 89, 2002.

Vasicek, J. M., H. V. Frey, and H. H. Thomas, Satellite magnetic anomalies and the Middle America Trench, Tectonophysics, 154, 19-24, 1988.

Wang, K. and T. Dixon, "Coupling" Semantics and Science in Earthquake Research, Eos Trans. AGU, 85(18), 4 May, 2004.

Yoshioka, S., T. Mikumo, V. Kostoglodov, K. M. Larson, A. R. Lowry, and S. K. Singh, Interplate coupling and a recent aseismic slow slip event in the Guerrero seismic gap of the Mexican subduction zone, as deduced from GPS data inversion using a Bayesian information criterion, Phys. Earth Planet. Inter., 146, 513-530, 2004.

Zumberge, J. F., F. H. Webb, M. B. Heflin, D. C. Jefferson, and M. M. Watkins, Precise point positioning for the efficient and robust analysis of GPS data from large networks, J. Geophys. Res., 102, 5005-5017, 1997.

S. I. Franco (e-mail: ivonne@ollin.igeofcu.unam.mx), V. Kostoglodov, K. M. Larson, V. C. Manea, M. Manea, and J. A. Santiago 